\title{
Valuing education during national public health week
}

\begin{abstract}
The attainment of a formal education is a strong positive social determinant associated with an elevated quality of health. It increases the accessibility to various support systems enabling individuals to proactively engage in preventive health care. A total of 48 human anatomy \& physiology students at Wayne County Community College District (WCCCD) filled out a public health assessment survey entitled "Healthiest Nation 2030" inquiring if they believed whether negative social determinants demonstrated a relationship to the level of student academic attainment and the quality of health. Data revealed that the majority of the surveyed WCCCD students did believe that negative social determinants adversely affected the level of educational attainment as well as the health status of a community. Their beliefs were compatible with data of previous studies pertaining to this public health matter of concern.
\end{abstract}

Keywords: education, public, health, community, association, students, specialists, scientific sessions, advocacy, webinars, legislation, policy makers, opportunities, financial freedom, federal policy, poster presentations
Volume 2 Issue 6 - 2015

\author{
Apryl Brown \\ Department of Biology, Michigan Community College Biologists, \\ USA
}

Correspondence: Apryl Brown, Department of Biology, Michigan Community College Biologists, Kappa Delta Pi, P.O. Box 442047 Detroit, USA, Email abrown2@wcccd.edu

Received: March 24, 2015 | Published: November 23, 2015
Abbreviations: WCCCD, Wayne county community college district; APHA, american public health association

\section{Introduction}

\section{American public health association}

The American Public Health Association (APHA) which is the oldest organization of its kind in the country is steadfast in the pursuit of transforming the United States into the healthiest nation in one generation-by 2030 especially involving endeavors of education and advocacy. APHA educational opportunities help maintain and/ or elevate the proficiency of public health specialists and students through webinars, learning institutes, scientific sessions involving oral and/or poster presentations, publication of public health articles, network with peers while serving on APHA boards, and participation in state affiliate public health associations. This continuing education enables public health specialists to keep abreast of current matters of concern in order for them to be knowledgeable of how to best educate their communities. ${ }^{1}$ APHA which is the only national public health organization to influence federal policy has adopted public health policies written and approved by APHA members and the APHA Governing Council, respectively, reflecting the organization's position on legislation issues. APHA participates in advocacy related endeavors by engaging with federal policy makers about public health legislation including visitations on Capitol Hill. Although the United States gross domestic product has a greater expenditure on health care in comparison to other developed countries numerous public health matters of concern including health disparity, health literacy, and health equity have manifested in epidemic proportions in both urban and rural communities across the nation. Becoming the healthiest nation around the globe involves collaborative nationwide participation of addressing the complete physical, mental, and social well-being of residents in our homeland. April 6th-12th was designated as the National Public Health Week where APHA partnered with organizations across the country educating the nationwide community how to elevate the health status of the United States. April 2015 was the 20th anniversary of APHA spearheading this national public health initiative.

\section{Education}

Many individuals do not realize that the level of educational attainment is a major positive social determinant related to the quality of health. Earning a high school diploma is a significant gateway that broadens the opportunities to afford the expenditures associated with a healthy lifestyle in comparison to the financial limitations imposed on many high school dropouts. ${ }^{2}$ High school graduates may seek the type of employment that requires the completion of a secondary education, and/or seek admission into postsecondary institutions of learning in order to intensify their proficiency in particular fields of study. Their undergraduate and/or graduate postsecondary education enables them to pursue careers of a higher socioeconomic status where they experience the financial freedom of embracing a healthy lifestyle consisting of adequate health care coverage, accessibility to health care, adequate social support systems to handle stress, affordability of eating nutritious meals, and association memberships conducive to physical fitness. ${ }^{3}$

\section{Methods}

The public health assessment survey entitled "Healthiest Nation 2030" was distributed out to 48 WCCCD students enrolled in human anatomy \& physiology where the majority of them were pursuing careers in biomedical science, health care, and/or public health. Their answers on the survey revealed whether they believed if the various social determinants possessed any impact on the level of educational attainment and/or health.

\section{Results}

The public health assessment survey entitled "Healthiest Nation 2030 " was distributed out to 48 WCCCD students enrolled in human anatomy \& physiology where the majority of them were pursuing careers in biomedical science, health care, and/or public health. Their 
answers on the survey revealed whether they believed if the various social determinants possessed any impact on the level of educational attainment and/or health.

\section{Demographic characteristics of the 48 WCCCD human anatomy \& physiology students}

i. Total Number of WCCCD Human Anatomy \& Physiology Female Students-37

ii. Age Range of WCCCD Human Anatomy \& Physiology Female Students 18-55 (Tables 1-7)

\section{Data from the WCCCD healthiest nation 2030 questionnaire}

a. Do you believe that the level of education has a direct relationship in elevating the health status of a community?

1. Female Yes $35 / 37=94.59 \%$ Female No $02 / 37=05.41 \%$

2. Male Yes $09 / 11=81.82 \%$ Male No $02 / 11=18.18 \%$

If you answered yes, please check all that apply (May include more than one checked response)

a. Higher Level of Income Female 19/37=51.35\% Male $5 / 11=45 / 45 \%$

b. Greater Health Coverage Female 18/37=48.64\% Male $3 / 11=27.27 \%$

c. Greater Access to Health Care Female 21/37=56.75\% Male $4 / 11=36.36 \%$

d. Greater Knowledge of Healthy Living Female 20/37=54.05\% Male $7 / 11=63.63 \%$

e. Greater Affordability of Healthy Living Female 15/37=40.54\% Male $4 / 11=36.36 \%$

f. Healthy and Safe Environment Female 17/37=45.95\% Male $5 / 11=45.45 \%$

g. Adequate Nutrition Female 16/37=43.24\% Male 5/11=45.45\%

h. Lower Levels of Stress Female 14/37=37.84\% Male 3/11=27.27\%

b. Do you feel that your academic major will lead to a career helping people or elevating the health status of a community?

1. Female Yes $35 / 37=94.59 \%$ Female No $02 / 37=05.41 \%$

2. Male Yes $09 / 11=81.82 \%$ Male No $02 / 11=18.18 \%$

c. Please describe your potential career goals (May include more than one checked response).

1. Research Females 6 Males 4

2. Clinical Health

1. Physician Females 6 Males 4

2. Nurse Females 20 Males 2

3. Pharmacist Female 0 Males 2

4. Dentist Female 0 Male 1

5. Therapist Females 7 Male 1

6. Technician Females 7 Males 2
1. Public Health Females 6 Male 1

2. Social Work Females 9 Male 1

3. Psychology Females 6 Males 2

d. Does homelessness or inadequate shelter affect the health status of a person?

1. Female Yes $36 / 37=97.30 \%$ Female No $01 / 37=2.70 \%$

2. Male Yes $10 / 11=90.91 \%$ Male No $01 / 11=9.09 \%$

e. Does homelessness or inadequate shelter affect the academic performance of a student?

1. Female Yes $35 / 37=94.59 \%$ Female No $02 / 37=05.41 \%$

2. Male Yes $10 / 11=90.91 \%$ Male No $01 / 11=09.09 \%$

f. Does a dysfunctional home environment affect the health status of a person?

1. Female Yes $36 / 37=97.30 \%$ Female No $01 / 37=2.70 \%$

2. Male Yes $10 / 11=90.01 \%$ Male No $01 / 11=09.09 \%$

g. Does a dysfunctional home environment affect the academic performance of a student?

1. Female Yes $35 / 37=94.59 \%$ Female No $02 / 37=05.41 \%$

2. Male Yes $09 / 11=81.82 \%$ Male No $02 / 11=18.18 \%$

h. Does a violent environment affect the academic performance of a student?

1. Female Yes $35 / 37=94.59 \%$ Female No $02 / 37=05.41 \%$

2. Male Yes $10 / 11=90.91 \%$ Male No $01 / 11=09.09 \%$

i. Does a violent environment affect the health status of a person?

1. Female Yes $32 / 37=86.49 \%$ Female No $05 / 37=13.51 \%$

2. Male Yes $08 / 11=72.73 \%$ Male No $03 / 11=27.27 \%$

j. Does bullying affect the academic performance of a student?

1. Female Yes $36 / 37=97.30 \%$ Female No $01 / 37=2.70 \%$

2. Male Yes $09 / 11=81.82 \%$ Male No $02 / 11=18.18 \%$

$\mathrm{k}$. Does bullying affect the health status of a person?

1. Female Yes $34 / 37=91.89 \%$ Female No $03 / 37=8.11 \%$

2. Male Yes $08 / 11=72.73 \%$ Male No $03 / 11=27.27 \%$

1. Do you think about nutrition on a regular basis?

1. Female Yes $25 / 37=67.57 \%$ Female No $12 / 37=32.43 \%$

2. Male Yes $09 / 11=81.82 \%$ Male No $02 / 11=18.18 \%$

m. Does social support affect the health status of a person?

1. Female Yes $27 / 37=72.97 \%$ Female No $10 / 37=27.03 \%$

2. Male Yes $07 / 11=63.64 \%$ Male No $04 / 11=36.36 \%$

n. Does social support affect the academic performance of a student?

1.Female Yes $26 / 37=70.27 \%$ Female No $11 / 37=29.73 \%$

2. Male Yes $03 / 11=27.27 \%$ Male No $08 / 11=72.73 \%$ 
o. Does a lack of adequate clothing affect the academic performance of a student?

1. Female Yes $19 / 37=51.35 \%$ Female No $18 / 37=48.65 \%$

2. Male Yes $02 / 11=18.18 \%$ Male No $09 / 11=81.82 \%$ p. Does a lack of adequate clothing affect the health status of a person?

1. Female Yes $22 / 37=59.46 \%$ Female No $15 / 37=40.54 \%$

2. Male Yes $05 / 11=45.45 \%$ Male No $06 / 11=54.55 \%$

Table I Total Number of WCCCD Human Anatomy \& Physiology Female Students - 37, Age Range of WCCCD Human Anatomy \& Physiology Female Students $18-55$

\begin{tabular}{llllll}
\hline & Age in years & Percentage of females & Age in years & Percentage of females \\
\hline I Female Student & 18 & $2.70 \%$ & 2 Female Students & 34 & $5.41 \%$ \\
2 Female Students & 19 & $5.41 \%$ & I Female Student & 35 & $2.70 \%$ \\
3 Female Students & 20 & $8.11 \%$ & 3 Female Students & 37 & $8.11 \%$ \\
3 Female Students & 21 & $8.11 \%$ & 2 Female Students & 38 & $5.41 \%$ \\
2 Female Students & 22 & $5.41 \%$ & I Female Student & 44 & $2.70 \%$ \\
3 Female Students & 23 & $8.11 \%$ & 2 Female Students & 45 & $5.41 \%$ \\
3 Female Students & 24 & $8.11 \%$ & I Female Student & 47 & $2.70 \%$ \\
3 Female Students & 25 & $8.11 \%$ & I Female Student & 5 I & $2.70 \%$ \\
I Female Student & 30 & $2.70 \%$ & I Female Student & 54 & $2.70 \%$ \\
I Female Student & 31 & $2.70 \%$ & I Female Student & 55 & $2.70 \%$
\end{tabular}

Table 2 Total Number of WCCCD Human Anatomy \& Physiology Male Students I I,Age Range ofWCCCD Human Anatomy \& Physiology Male Students I9-40

\begin{tabular}{lll}
\hline & Age in years & Percentage of males \\
\hline I Male Student & 19 & $9.09 \%$ \\
I Male Student & 20 & $9.09 \%$ \\
2 Male Students & 22 & $18.19 \%$ \\
I Male Student & 23 & $9.09 \%$ \\
3 Male Students & 24 & $27.27 \%$ \\
I Male Student & 25 & $9.09 \%$ \\
I Male Student & 33 & $9.09 \%$ \\
I Male Student & 40 & $9.09 \%$ \\
\hline
\end{tabular}

Table 3 Ethnicity (As Reported by WCCCD Students)

\begin{tabular}{lllll}
\hline Hispanic or Latino of any race & Female & $\mathbf{0}$ & Male & $\mathbf{1}$ \\
\hline Non-Hispanic or Latino of Any Race & Females & 24 & Males & 7 \\
Declined to Answer & Females & 13 & Males & 3 \\
\hline
\end{tabular}


Table 4 Race (As Reported by WCCCD Students)

\begin{tabular}{lll}
\hline $\begin{array}{l}\text { Black (Not African American) } \\
\text { African American }\end{array}$ & Female I & Male I \\
White or Caucasian American & Female I & Male I \\
Arab American & Female I & Males 3 \\
Asian & Females 3 & Male I \\
Multiracial & Female 3 & Male I \\
Declined to Answer & Females 4 & Males 3 \\
\hline
\end{tabular}

Table 5 Employment

\begin{tabular}{lllll}
\hline Not Working & Females & I I & Males & $\mathbf{3}$ \\
\hline Part-Time Employment & Females & 15 & Males & 3 \\
Full-Time Employment & Females & 10 & Males & 5 \\
Declined to Answer & Female & I & Male & 0 \\
\hline
\end{tabular}

Table 6 Level of Income

\begin{tabular}{|c|c|c|c|c|}
\hline $0-\$ 5000 /$ year & Females & 7 & Males & 2 \\
\hline$\$ 5000-\$ 10,000 /$ year & Females & 8 & Male & I \\
\hline$\$ 10,001-\$ 25,000 /$ year & Females & 7 & Male & I \\
\hline$\$ 25,001-\$ \$ 35,000 /$ year & Females & 5 & Male & I \\
\hline$\$ 35,001-\$ 50,000 /$ year & Females & 3 & Male & I \\
\hline$\$ 50,001-\$ 65,000 /$ year & Female & I & Male & I \\
\hline$\$ 65,001-\$ 80,000 /$ year & Females & 2 & Male & I \\
\hline Declined to answer & Females & 4 & Males & 3 \\
\hline
\end{tabular}

Table 7 Level of Education

\begin{tabular}{lllll}
\hline $\begin{array}{l}\text { High school diploma or } \\
\text { equivalent }\end{array}$ & Females & $\mathbf{3 7}$ & Males & $\mathbf{1 1}$ \\
\hline Associate Degree Candidates & Females & 33 & Males & 9 \\
Associate Degree Earned & Female & 2 & Males & 0 \\
Bachelor Degree Candidates & Female & I & Males & 0 \\
Bachelor Degree Earned & Female & I & Males & 2 \\
\hline
\end{tabular}

\section{Discussion}

Data from the survey entitled "Healthiest Nation 2030" revealed that both the male and female WCCCD students enrolled in human anatomy and physiology believed that negative social determinants could hinder the level of educational attainment leading to students becoming high school dropouts and experiencing lives affiliated with a lower socioeconomic status and suboptimal health. The educational attainment of earning a high school diploma is often considered the door of opportunity of being able to experience a life associated with an optimal quality of health. High school graduates qualify as candidates for admission into postsecondary institutions of learning where upon graduation they experience diverse career opportunities and an enhanced quality of life as they have successfully accomplished their goals.

\section{High school dropouts}

Untreated and/or undiagnosed physical and mental illnesses, behavioral problems, and negative social determinants such as lack of social support, hazard environmental conditions, dysfunctional home environment, teenage pregnancy, bullying, substance abuse, violence, hunger and/or malnutrition, homelessness and/or inadequate safe shelter, and lack of adequate clothing may hinder the progress of academic achievement that is needed for students to qualify for high school graduation.

High school dropouts who usually only qualify to work in low paying occupations sometimes affiliated with hazard conditions are more often members of the lower socioeconomic status. They usually spend their limited incomes on immediate matters of concern that are needed to sustain their survival such as housing, food, clothing, and possibly transportation. The epidemic manifestation of preventable chronic disorders such as obesity, malnutrition, heart disease, and diabetes mellitus have resulted in the manifestation of health disparities especially among individuals of the lower socioeconomic status who usually have a low level of educational attainment. ${ }^{1,46}$ Due to the lack of finances, accessibility, and immediate concern they have not proactively sought out the importance and understanding of embracing a healthy lifestyle consisting of preventive health care which often leads to the onset of health disparities. Less educated workers in low paying occupations lack adequate accessibility to health care, employer sponsored full health coverage if offered any, and job related benefits including paid sick and personal leave as well as retirement pension. ${ }^{7}$

Health literacy has become an issue of concern among individuals of a low educational attainment since they may lack the accessibility to educational resources such as health literature, health awareness programs, health seminars, and social media preventing them from being able to make adequate informed decisions concerning their well-being. They may lack the ability to read and comprehend health literature even when written in layman terminology. Health illiterate patients are more often noncompliant in maintaining their health since they do not fully comprehend and/or remember how to adequately adhere to their medical regimens once they have left the facilities of their health care providers. ${ }^{8-10}$

\section{A postsecondary education}

A formal postsecondary education is often associated with a higher socioeconomic status where individuals of this financial standing more often experience adequate health coverage, a greater accessibility to health care, better housing in cleaner and safe neighborhoods, adequate transportation, financial savings, career with job related benefits, adequate social support, healthy options to handle stress related circumstances, and the affordability to embrace a healthy lifestyle comprise of nutritious meals, traits of healthy behavior, and various health related activities providing physical and mental fitness. Communities composed of a majority high socioeconomic population are directly related to a decrease in health disparity as a result of being able to afford the lifestyle of adhering to preventive health care. ${ }^{11}$

The educated population which is more able to obtain and understand basic health information is more empowered to make wise informed decisions concerning personal health. The educated 
population is more able to afford engaging in preventive health care such as eating nutritious meals which may be more expensive in comparison to the less expensive foods purchased from fast food restaurants. The educated population possesses greater accessibility to social media by owning computers with internet access in order to seek information. The possession of adequate transportation enables the educated population to attend health awareness programs, health seminars, and health lectures of prominent health care and/or public health professionals. ${ }^{12}$ These individuals have a greater accessibility of endowing themselves with knowledge through consultations with the health care providers of their choice. Educated patients may be more compliant in adhering to their health care regimens through to their enhance ability to comprehend prescription directions, health literature, consent forms, and directions of their health care providers. ${ }^{13}$

\section{Conclusion}

Studies have shown that a formal postsecondary education is associated with a high quality of health. It is imperative for interdisciplinary teams of educators and health care and/or public health specialists to collaboratively work together in order to effectively analyze how to counter attack the negative social determinants impeding the progress of educational attainment for high school students. In their pursuit of becoming biomedical scientists, health care and/or public health professionals, WCCCD students visualized their future career goals of helping people and working to elevate the health status of the community in which they will serve. WCCCD students were studying to become part of a well diverse and developed science and/or health related workforce collaboratively working to produce a healthier community, and state as well as nation.

\section{Acknowledgements}

I thank the WCCCD human anatomy \& physiology students for their participating in taking the survey and their eagerness to learn. I thank the WCCCD administration and faculty for their support in creating an excellent learning environment for the WCCCD students. I thank APHA for spearheading the National Public Health Week in order to help the United States become the healthiest nation in one generation.

\section{Conflict of interest}

The author declares no conflict of interest.

\section{References}

1. RWJF Commission to Build a Healthier America. Education Matters for Health. Issue Brief 6: Education and Health. 2009.

2. Nicholas Freudenberg N, Rugis J. Reframing School Dropout as a Public Health Issue. Prev Chronic Dis. 2007;4(4):A107.

3. Woolf SH, Johnson RE, Phillips RL, et al. Giving everyone the health of the educated: an examination of whether social change would save more lives than medical advances. Am J Public Health. 2007;97(4):679-683.

4. Coordinated school health programs. USA: Centers for Disease Control and Prevention, National Center for Chronic Disease Prevention and Health Promotion; 2006.

5. Somers C, Piliawshky M. Drop-out prevention among urban, African American adolescents: program evaluation and practical implications. Preventing School Failure. 2004;48:17-22.

6. Rumberger RW. Why students drop out of school. In: Orfield G, editor. Dropouts in America: confronting the graduation rate crisis. USA: Harvard Education; 2004. p. 131-156.

7. Deaton A. Policy implications of the gradient of health and wealth Health Aff (Millwood). 2002;21(2):13-30.

8. Rumberger RW, Thomas SL. The distribution of dropout and turnover rates among urban and suburban high schools. Sociol Educ. 2000;73:3967.

9. Ross C, Wu C. The links between education and health. Am Sociol Rev. 1995;60:719-745

10. Brooks-Gunn J, Guo G, Furstenberg F. Who drops out of and who continues beyond high school? A 20 year follow-up of black urban youth. J Res Adolesc. 1993;3:271-294.

11. Winkleby M, Jatulis D, Frank E, et al. Socioeconomic status and health: how education, income, and occupation contribute to risk factors for cardiovascular disease. Am J Public Health. 1992;82(6):816-820.

12. Fine M. Why urban adolescents drop into and out of public health school. Teach Coll Rec. 1986;87:393-409

13. American Public Health Association 